\title{
Imagem, Pesquisa e Antropologia
}

Andréa Barbosa

UNIFESP, São Paulo, SP, Brasil ${ }^{1}$

Como refletir criticamente sobre o encontro entre a Antropologia e as linguagens audiovisuais na contemporaneidade? Em novembro de 2013 realizamos, na Escola de Filosofia, Letras e Ciências Humanas da Universidade Federal de São Paulo, um evento homônimo ao título deste dossiê onde foram levantados e debatidos alguns possíveis caminhos para responder a esta questão. $^{2}$

$\mathrm{Na}$ longa trajetória da produção acadêmico-científica da Antropologia, a utilização das imagens na pesquisa sempre causou, no mínimo, um estranhamento. A relação estabelecida sempre foi e, em alguma medida, continua sendo, de resistência à sua qualidade epistemológica, uma relação difícil para relembrar o título de um artigo de Sylvia Caiuby Novaes (2009). Algumas vezes, a dificuldade parece estar centralizada na dicotomia entre objetividade e subjetividade. Os propósitos científicos buscam a precisão e a objetividade como meios privilegiados de apreender e compreeder a realidade e, nesse sentido, a polissemia da imagem parece se tornar um obstáculo. Outras vezes, parece estar localizada no duplo desafio que empreender uma pesquisa a partir ou junto à linguagens expressivas impõe: de um lado dar conta das questões antropológicas que ambicionamos enfrentar e, de outro, dar conta também das questões cognitivas que lançar mão dessas linguagens provoca.

Entretanto, na prática, os esforços de investigação e utilização das imagens buscando nelas, ou com elas, soluções metodológicas para lidar com as problemáticas sociais contemporâneas, e não a sua percepção como obstáculo à objetividade, tem sido cada vez mais frequentes. $\mathrm{Na}$ Antropologia, arriscaria dizer que, nos últimos quarenta anos, a imagem vem ganhando centra-

1 Contato: acmmb66@gmail.com; http://visurb-unifesp.wix.com/visurb-unifesp

2 Agradeço enormemente a todos os pesquisadores do VISURB (Grupo de Pesquisas Visuais e Urbanas da UNIFESP) pela organização do Seminário Imagem, Pesquisa e Antropologia, pela curiosidade intelectual que move tanto as reflexões do grupo, como as do seminário e as do próprio texto aqui apresentado, em especial Rafael Acácio de Freitas, Débora Costa Faria, Marcela Vasco, Juliane Yamanaka, Paula Harumi Kakazu, Erika Paula dos Santos, Fernanda Matos, Janaína Andrade, Denise Ferreira, Fernando Filho, Rodrigo Baroni, Fábio Silva, Lindolfo Sanches, Pamella Bravo. 
lidade, surgindo como uma aposta no poder e potencial desta linguagem para compreensão das realidades sociais (MacDougall, 2006). Este campo, que pode assumir denominações diversas como, por exemplo, Antropologia Visual, Antropologia da Imagem, Antropologia Audiovisual, é um campo consolidado com um lastro de reflexões importantes sobre a construção de conhecimento antropológico.

Pensar as possibilidades do uso das imagens na reflexão antropológica implica entender a imagem como forma específica de linguagem, que se diferencia a partir dos diferentes meios que a vinculam. Entender o discurso cinematográfico, fotográfico ou do desenho, por exemplo. E como desdobramento necessário, implica também entender a emergência histórica da Antropologia Visual, verificar as questões metodológicas e epistemológicas que este campo tem agregado à discussão mais ampla da Antropologia.

Ao refletirmos sobre os uso das imagens a partir da consideração dos esforços da Antropologia Visual ao longo de sua trajetória, podemos recuperar brevemente alguns momentos decisivos para sua constituição. No início do Século XX, a Antropologia moderna já se lançava em direção a intensidade do encontro e da intersubjetividade, ao encurtar a distância física entre os povos e culturas levando para o campo o teórico, o antropólogo e o observador unidos na mesma figura que vai realizar suas pesquisas. Esse movimento parece ter sido essencial para a gradual percepção da dicotomia entre o Eu e o Outro, a fronteira dura da alteridade que contribuía, em grande medida, para reprodução etnocêntrica do mundo, dificultando a apreensão e interpretação do humano pelas suas diferenças.

Com esse primeiro passo em direção a ampliação das possibilidades do humano inicia assim um caminho da Antropologia para considerações mais amplas de seu instrumental de coleta, análise, interpretação e difusão dos dados recolhidos em campo. E quando associados a uma tecnologia e linguagem da produção de imagens, as investigações antropológicas ganham novas possibilidades.

Se a imagem fotográfica e a antropologia nascem praticamente juntas, durante o século XIX, é com a complexificação das formulações dos problemas, perspectivas e práticas antropológicas do século seguinte que a imagem e a antropologia começam um diálogo fértil, culminando com a consolidação de uma antropologia especificamente visual. A princípio, como nova possibilidade metodológica de registro do trabalho de campo, paulatinamente a imagem começa a se insinuar como linguagem capaz de contribuir para uma melhor comunicação intercultural e provocar novas questões que se desdobram em práticas antropológicas variadas como as de Malinowski, Margaret Mead e Jean Rouch.

Hoje, analisando a utilização seminal das fotográficas nos relatos etnográficos, como em Os Argonautas do Pacífico Ocidental de Malinowski, temos a sensação de poder apreender, mesmo que por instantes, todo esse potencial de linguagem, de narrativa visual, de nova contribuição epistemológica para toda a Antropologia. Mesmo considerando que seu uso das imagens fotográficas parece ser bastante ingênuo e ilustrativo, hoje amplamente criticável como uma utilização reducionista da imagem, como simples „prova“ do „eu estive lá“, as fotografias se rebelam contra essa apropriação reducionista e nos abrem a possibilidade de perceber um olhar outro que retorna ao antropólogo. Ao vermos a troca de olhares entre fotógrafo e fotografados, a disposição dos corpos em relação a uma cena que se constrói, um fora de campo que se insinua, somos despertados por essas imagens para uma sensação provocadora. A sensação de que o uso seminal 
da fotografia para a reflexão antropológica das diferentes culturas que compõem a humanidade realizada por Malinowski aguardavam um leitor que ainda não existia. ${ }^{3}$ Um leitor capaz de conhecer e aprender pela e com a imagem, capaz de ler a imagem e as complexas relações que esta constrói com a realidade insinuada nela (e também as que ela constrói com outras imagens num universo muito particular), de considerar a imagem como capaz de explicitar a complexa relação entre objetividade e subjetividade presente na experiência da realidade, mesmo que através de um breve „sopro“, provisório e efêmero, mas suficiente para revelar tanto a complexidade da realidade quanto o potencial da imagem para compreendê-la imaginativamente. Um leitor que entenderia o „risco“ da subjetividade ligado à imagem como uma oportunidade de conhecer.

Passados mais de 80 anos da experiência de Malinowski, o uso da fotografia acumulou muitas possibilidades na sua relação com o campo etnográfico. Das metodologias visuais participativas às fotoetnografias, a imagem fotográfica se embrenhou no fazer do antropólogo que, atento à construção das relações no processo de pesquisa, coloca a produção de imagens no centro dessas relações.

O ato de fotografar em contextos etnográficos é levado ao seu limite como índice das relações construídas em campo na produção de retratos. O olhar que pede, o olhar que assente, o olhar que inquire e o que nega. Buscando refletir sobre o uso do retrato na pesquisa antropológica, Fernanda Rechenberg traz em seu artigo, presente neste dossiê - „Notas etnográficas sobre o retrato: repensando as práticas de documentação fotográfica em uma experiência de produção compartilhada das imagens" - uma reflexão sobre sua pesquisa realizada na cidade de Porto Alegre, RS. A partir da atuação em um projeto de elaboração de retratos de família no bairro Vila Jardim, a autora levanta questões metodológicas sobre a produção de retratos na pesquisa etnográfica. Qual a realidade desses retratos? Ou melhor, qual a sua verdade? Eles falam de quem? Para quem? Qual seria a questão incontornável da fotografia? Os retratos trazidos por Fernanda Rechenberg são bons para pensar a potência imaginativa da fotografia e das relações implicadas na sua elaboração. $\mathrm{O}$ retrato aqui não é apenas um ato, mas um processo de muitos atos. Um processo que assume o risco da construção intersubjetiva na qual se baseia.

Se ao olhar as fotografias de Malinowski nos acomete a sensação de que elas aguardavam um leitor mais desperto para as questões epistemológicas que a imagem pode provocar, esta sensação não é diferente com as imagens em movimento, do primeiro cinema. É nesse encontro, cinema e antropologia, concretizado desde os fins do século XIX, e valorizado ao longo da história da disciplina que a sua vertente visual se institucionaliza, e logo surgem leitores e espectadores dispostos a enfrentar os riscos desse encontro entre imagem e Antropologia, como oportunidade cognitiva. O cinema parece, portanto, estar na origem do que hoje chamamos de Antropologia Visual, todo o ambicioso objetivo de estabelecer o diálogo entre o rigor científico e a arte cinematográfica ganha reconhecimento e aceitação nas Universidades, mesmo que através de um debate que se estende indefinidamente para a definição do que é o filme etnográfico. Estamos nos referindo aqui a um cinema feito por antropólogos, contudo, há toda uma gama de possibilidades na relação entre cinema e pesquisa antropológica que não se esgota nessa produção. Falamos das análises antropológicas de filmes produzidos fora da academia e sem nenhum propósito científico. As análises desses filmes são pertinentes justamente porque evidenciam a realidade como criação imaginativa. Evidenciam que esses universos imagéticos participam da

3 O antropólogo Etienne Samain foi um desses leitores esperados e escreveu um instigante artigo sobre essas fotografias (1995). 
construção social e cultural da realidade. Os filmes podem tornar-se, portanto, interlocutores privilegiados.

As imagens em movimento foram ganhando centralidade na trajetória da Antropologia Visual, no entanto, essa proeminência também parece ter anunciado seus limites. É justamente com o objetivo de refletir sobre a potência das imagens fotográficas e seu silêncio em contraste com a palavra em evidência de um tipo de documentário etnográfico predominante na produção acadêmica que Sylvia Caiuby Novaes apresenta seu ensaio „O silêncio eloquente das imagens fotográficas e sua importância na etnografia“. A autora argumenta que diferentemente do vídeo ou filme etnográfico, que vem sendo cada vez mais utilizado em pesquisas, as fotos permanecem mudas. Talvez por isso mesmo as fotografias venham sendo menos utilizadas do que os filmes na antropologia, que permanece uma disciplina de palavras, diz a autora concordando e atualizando uma formulação, dos anos de 1970, da antropóloga norte-americana e uma das maiores entusiastas do uso das imagens por antropólogos, Margaret Mead (1995).

Se a forma de mobilizar silêncios e palavras nas imagens com as quais lidamos na pesquisa evidenciam que tipo de antropologia está sendo praticada, o ritmo que se imprime ao trabalho com elas também o faz. O ensaio de Marcus Banks se debruça sobre esse ritmo da investigação, particularmente no que diz respeito ao papel desempenhado pelos filmes e pelas fotografias na criação ou subversão desse ritmo. Em „Slow Research: exploring one's own visual archive“, o autor revisita seu arquivo visual pessoal de mais de vinte anos de pesquisa na Índia buscando possibilidades para que fotografias e outras imagens possam ser reabertas a fim de provocar novos insights. Aqui o deslocamento no tempo e no espaço é colocado no centro da questão. Não o deslocamento clássico entre „o estar lá“ e o „estar aqui“ do fazer etnográfico, mas o deslocamento epistemológico do olhar do fotógrafo/antropólogo que cede lugar ao olhar entre as imagens que se deslocam de seus contextos etnográficos de origem para se aventurar por novos sentidos.

Ainda outra prática etnográfica que lança mão das imagens insurge a nos provocar. Os diários gráficos de campo, ou melhor dizendo, a presença do desenho na etnografia. A produção de desenhos é uma ferramenta com enorme potencial de contribuição para o conhecimento etnográfico, tanto como forma de acesso ao universo dos interlocutores, como um campo possível para a intersecção das subjetividades em jogo, a do antropólogo e a dos interlocutores. O processo de desenhar impõe um ritmo diferente na investigação, favorecendo interações e colocando o etnólogo numa situação de exposição do seu próprio fazer. $\mathrm{O}$ ato em si de desenhar, por sua vez, requer um reaprendizado do olhar sobre o mundo, capaz de produzir não apenas registros gráficos daquilo que se olha, mas também apreender os conceitos e valores do universo investigado que fundamentam esse registro. Karina Kushnir explora em seu artigo „Ensinando antropólogos a desenhar: uma experiência didática e de pesquisa" alguns resultados de sua experiência de ensino que propõe o desenho como ferramenta central para a pesquisa etnográfica. Alunos sem formação prévia na área foram incentivados a desenhar como uma forma de conhecer o mundo. Através de oficinas práticas, as convenções em torno do desenho acabaram desconstruídas para, em seu lugar, serem reencontradas novas formas narrativas capazes de evocar graficamente ideias, encontros, diálogos, observações e percepções sobre a vida social. A experiência partiu da sala de aula para, posteriormente, explorar espaços na cidade do Rio de Janeiro, tendo como pano de fundo o desafio de compreender a cidade e os múltiplos pontos de vista que se enfrentam no espaço urbano. 
Nas últimas duas décadas uma perspectiva que foge à lógica da representação e que, por isso, amplia as possibilidades de lidar com as imagens como seres viventes, nos abre os horizontes da nossa antropologia das e com imagens. Essa é a perspectiva que Etienne Samain traz em seu ensaio „Antropologia, imagens e arte. Um percurso reflexivo a partir de Georges Didi-Huberman“. As fronteiras entre História da Arte, imagens e Antropologia foram felizmente abaladas. Na virada cognitiva visual da qual participamos, essas ciências - Antropologia e Historia da Arte - outrora distintas, vão redescobrindo a natureza e os horizontes de seus próprios começos. Neste ensaio, o autor retraça algumas das etapas de sua própria descoberta e exploração das relações entre antropologia, imagens e arte, remetendo às importantes contribuições de Gregory Bateson, Claude Lévi-Strauss, Alfred Gell, Hans Belting, William J. T. Mitchell. Abre, em seguida, um novo espaço crítico, que conduz à obra humanistica de Georges Didi-Huberman, quando, na linhagem de Aby Warburg e de Walter Benjamin, esse filósofo e historiador da arte trata de situar as imagens e o saber visual como sendo um campo privilegiado de questionamentos sobre nossa história, apelos e gritos para tomar posição em nome do porvir de nosso planeta.

Mesmo com essa trajetória heterogênea podemos formular, de maneira mais geral, que os desafios teórico-metodológicos do uso da imagem sob a perspectiva antropológica levaram à complexificação dessa relação: imagem e pesquisa. A sua utilização como mero registro ou ilustração do argumento desenvolvido no texto acadêmico tornou-se apenas uma possibilidade, considerada ainda como simplista, quando vislumbrada as potencialidades desse meio, imagético, para atingir os objetivos de pesquisa ligados à compreensão e interpretação das realidades sociais. Assim, novos caminhos enriqueceram a discussão, abrindo novos horizontes e possibilitando a dissolução de problemas e obstáculos de ordem metodológica e epistemológica e criando outros desafios. Dentre eles, o uso da imagem como instrumento de pesquisa, através da utilização de fotos e vídeos não apenas como registro de observação, mas também como elementos que permitem a criação de um setting etnográfico específico; como elemento a ser incorporado na análise de uma realidade específica; como forma expressiva de um percurso de pesquisa, enfim, as imagens como formas que pensam e nos ajudam a pensar antropologicamente.

O último ensaio deste dossiê é um ensaio visual. Imagens provocativas. $\mathrm{O}$ carnaval é tempo de festa, mas também de trabalho. Esta imersão fotoetnográfica, realizada por um „cordeiro da Bahia“, literalmente enfoca a maior categoria de trabalhadores do carnaval de Salvador, os cordeiros de bloco. Como o autor mesmo nos adverte, „puxar“ corda de bloco não é tarefa para qualquer um. Precisa estar curtido pela vida, gordo de fome, para ter coragem de enfrentar a multidão que se espreme nos circuitos. O carnaval é também tempo de festa para os cordeiros que labutam, fantasiados, enfeitados, cantam e dançam, namoram e bebem, enquanto puxam a corda de açoite, símbolo do moderno carnaval de Salvador. „Cordeiros da Bahia, festa e trabalho nas cordas do carnaval“ de Haroldo Abrantes não é apenas para ser visto. É para ser olhado e enxergado. ${ }^{4}$ Ver é mobilizar nossa competência visual, mas olhar é mobilizar nossas referências interpretativas, é o olhar que tem corpo e história. Enxergar é ir além disso, é mobilizar questões que inquirem as imagens para além do visto e olhado. É a transvisão de Manoel de Barros, ${ }^{5}$ aquela que une memória, imaginação e criação.

4 Uma reflexão mais detida sobre essas três possibilidades epistemológicas está melhor desenvolvida em Barbosa (2012).

5 „O olho vê, a memória revê e a imaginação transvê" fala do poeta Matogrossense Manoel da Barros no filme Janela da Alma de João Jardim e Walter Carvalho (2001). 
É justamente nesse sentido, plural e criativo, que em nosso contexto brasileiro, surgem diversas iniciativas e núcleos, o que demonstra o avanço da Antropologia Visual no país e também a conquista de terreno da imagem nas Ciências Sociais. O que reforça a pertinência deste dossiê, que apresenta um conjunto de reflexões sobre experiências de pesquisas com imagens, abrindo-se para explorar as suas questões e potencialidades.

\section{Biblografia}

Barbosa, Andrea. 2012. São Paulo Cidade Azul. São Paulo: Alameda Casa Editorial.

Caiuby Novaes, Sylvia. 2009. „Imagem e Ciências Sociais: trajetória de uma relação difícil“. Pp. 35-59 in Imagem-conhecimento, editado por Andrea Barbosa, Edgar Cunha e Rose Satiko Gitirana Hikiji. Campinas: Papirus.

Samain, Etienne Ghislain. 1995., Ver e Dizer na Tradição Antropológica. Bronislaw Malinowski e a Fotografia." Horizontes Antropológicos v. 2: 19-48.

MacDougall, David. 2006. Corporeal Image. Princeton and Oxford: Princeton University Press. Mead, Margaret. 1995. „Visual Anthropology in a Discipline of Words.“. Pp. 3-10 in Principles of Visual Anthropology, editado por Paul Hockings. New York: Mouton de Gruyter. 